\title{
Pathological and clinical findings in a series of 67 cases of medullary carcinoma of the thyroid
}

\author{
E. D. WILliamS ${ }^{1}$, C. L. BROWN, AND I. DONIACH \\ From the Institute of Pathology, The London Hospital
}

SYNOPSIS The pathological features of 67 cases of medullary carcinoma of the thyroid were studied, and when possible the case histories were reviewed.

The typical tumour is sharply demarcated but not encapsulated, is composed of sheets of cells having eosinophilic granular cytoplasm, with the deposition of amyloid in the stroma. We would stress the frequency of binucleate cells, the scarcity of mitoses, and the frequent occurrence of calcification.

The clinical findings show a wide variation in age at presentation of this tumour, and a wide variation in prognosis, with a mean survival from the time of presentation to hospital of 6.6 years, the longest being 21 years. Two of this group of patients also had phaeochromocytomas; these two and three others showed small papillary tumours of the eyelids, lips, and tongue.

Despite the variation in some of its characteristics, medullary carcinoma of the thyroid is considered to be a distinct and sharply defined entity. It appears to be the only type of thyroid carcinoma associated with phaeochromocytoma, the only type associated with multiple mucosal neuromas and the only type with a familial incidence. These findings emphasize the validity of its separation from other types of thyroid carcinoma.

Thyroid carcinomas have for many years been generally classified into a differentiated group of papillary and follicular carcinomas and an anaplastic group. Various authors have noted that there is a small group of tumours which may appear histologically undifferentiated but which have a much better prognosis than the typical anaplastic thyroid carcinoma.

Horn described a small series of these cases in 1951, and Laskowski in 1957 proposed the name 'carcinoma thyroideum hyalinicum' for this type of tumour. Hazard, Hawk, and Crile, in 1959, clearly defined the major histological features of this tumour in a study of 21 cases and recognized the diagnostic importance of the regular occurrence of amyloid in the stroma. They also commented on the relatively good prognosis and suggested the name 'medullary carcinoma of the thyroid'. Since their description, this type of tumour has been classified as a separate type in the major studies of thyroid carcinoma, and Woolner, Beahrs, Black, McConahey, and Keating (1961) found 57 examples in a survey of

\footnotetext{
'Present address: The Department of Pathology, Postgraduate Medical School, Hammersmith Hospital, London.

Received for publication 29 September 1965.
}

885 cases of thyroid carcinoma. These authors referred to the tumour as 'solid carcinoma with amyloid stroma' rather than medullary carcinoma. Because of the prognostic importance of recognizing this type of tumour histologically and because a number of cases with unusual associated diseases came to our attention, we decided to analyse the histological features of a large series of medullary carcinoma of the thyroid and study the available clinical records and follow-up.

Sixty-seven examples of medullary carcinoma of the thyroid were studied histologically. Twenty-two were from the London Hospital; the rest were obtained from the files of four other London hospitals and from a number of individual pathologists who kindly sent in material. A major criterion for the inclusion of a case within the series was the presence of amyloid in the stroma of the tumour. In the great majority of cases amyloid was identified by at least two of the three generally used histological techniques for this substance, methyl violet, congo red, and thioflavin $T$. In two cases thioflavin $T$ alone gave a positive result. In four cases only sections stained with haemalum and eosin were available; in these amyloid was identified by its amorphous 
eosinophilic appearance and by the development of anomalous colours when the sections were viewed between crossed polaroids (Brewer, 1964). This technique was also used with the Congo-Red stained sections (Ladewig, 1945).

\section{PATHOLOGICAL FINDINGS}

The typical medullary carcinoma of the thyroid is a firm, rounded tumour up to $8 \mathrm{~cm}$. in diameter, lying within the substance of the thyroid lobe. On cross section the tumour is grey-white, often gritty, and is usually sharply demarcated from the adjacent normal thyroid. A few cases were described as encapsulated, and in some an ill-defined lobulation was seen.

Microscopically the tumour is made up of sheets and nests of regular eosinophilic granular cells, separated by a fibrous stroma containing irregular masses of amyloid (Fig. 1). Some of the specific features will now be considered in more detail.

\section{CYTOLOGY}

The typical cell has an ill-defined cytoplasmic membrane and plentiful finely granular eosinophilic cytoplasm (Fig. 2). The nucleus is central, averaging $8 \mu$ in diameter, with a speckled chromatin pattern; the nucleoli are not prominent. Binucleate cells are almost invariably present and cells with three or more nuclei are not infrequent. A moderate degree of variation in nuclear size is usual and may sometimes be marked (Fig. 3). Mitoses are infrequent: they were seen after careful search in 26 tumours, in only six were they found easily.

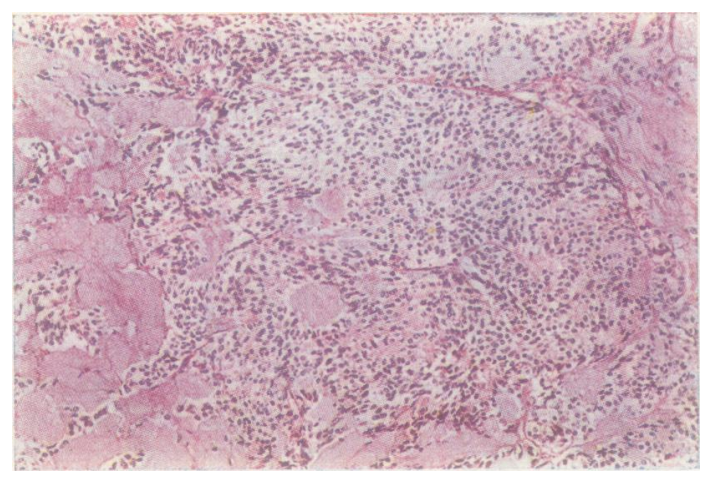

FIG. 1.
In well-fixed tissue the commonest appearan was of closely packed polygonal cells. In poorly-fixed tissue, cell shrinkage occasionally led to separation with a single layer of cells remaining attached to tbe connective tissue trabeculae giving a pseudopapillary appearance (Fig. 4). A second cell type seen in just over half the tumours; these cells wepe elongated, with oval, often hyperchromatic nuchei (Fig. 5), sometimes showing a whorled pattern and sometimes the streaming pattern described in oat-cell carcinomas (Fig. 6). Although intermediate cell typess between these spindle-shaped cells and the typiw polygonal cell were not uncommon, the two typos usually occurred in distinct areas within any one tumour. In 14 cases the spindle cell pattern was the dominant one. Within the islands of spindle cell tumour small clear vacuoles were frequently seen; some cases these appeared to be the result of vacuolation within the cytoplasm of macrophages (Fig. 7).

While in most tumours the polygonal cells we arranged in irregular sheets or broad trabeculae with no definite pattern, in some regular cellular arrang $\overrightarrow{\text { - }}$ ments were present. In four cases well-mark\&g palisading of the peripheral cells of the tumour clumps was seen (Fig. 8); in other instances oa tendency for the nuclei of the peripheral cells to towards the inner side of the cell was noted. The type of nuclear palisading seen in neurilemmomits which has previously been described in this tumour (Russell, Ibanez, Clark, and White, 1963) was seên only to a minor degree. In some areas of a few casess the sheets of polygonal cells were regular in size agid separated by a thin connective tissue network, preducing a pattern reminiscent of a carcinoid tumo하,

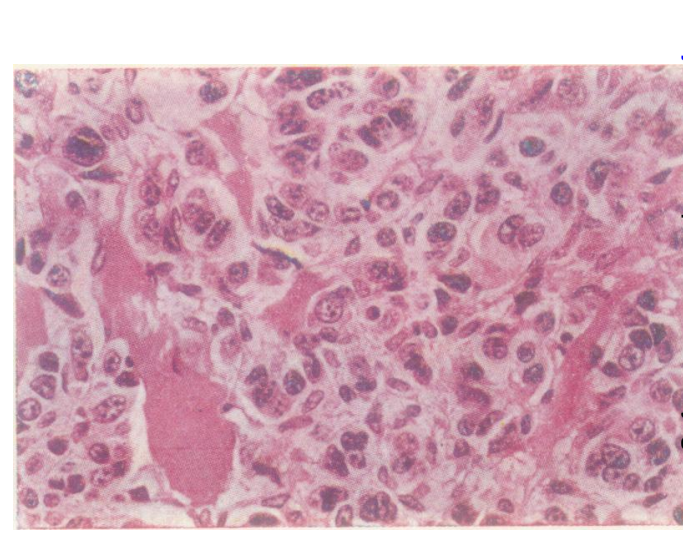

FIG. 2.

FIG. 1. Typical field of a medullary carcinoma showing sheets of uniform tumour cells and eosinophilic nodüar deposits of amyloid. H.E. $\times 160$.

FIG. 2. High-power field of a typical medullary carcinoma showing amyloid deposits and tumour cells with plentififl finely granular cytoplasm, some nuclear variation and occasional multinucleate forms. H.E. $\times 640$. 


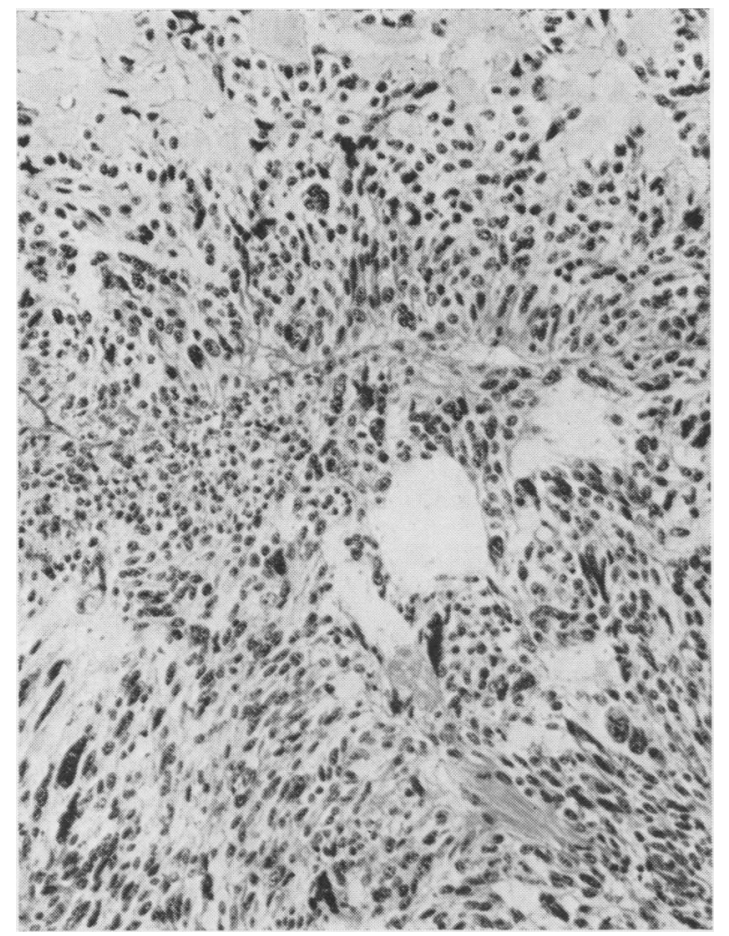

FIG. 3. H.E. $\times 160$. Medullary carcinoma showing an unusually high degree of nuclear variation of tumour.

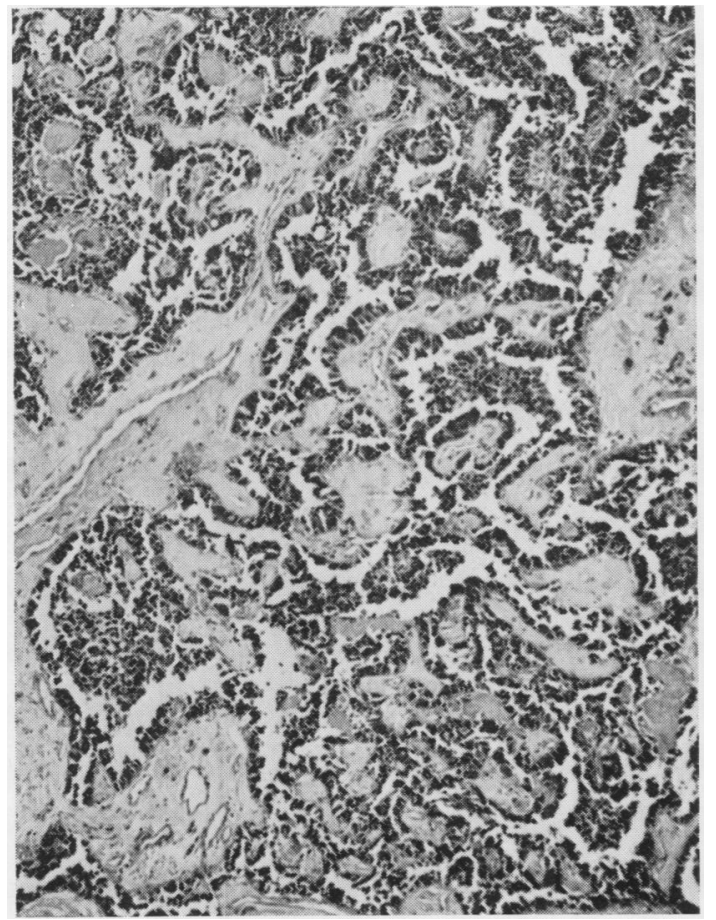

FIG. 4. H.E. $\times 50$. An area of medullary carcinoma in which shrinkage has led to pseudo-papillary appearance.

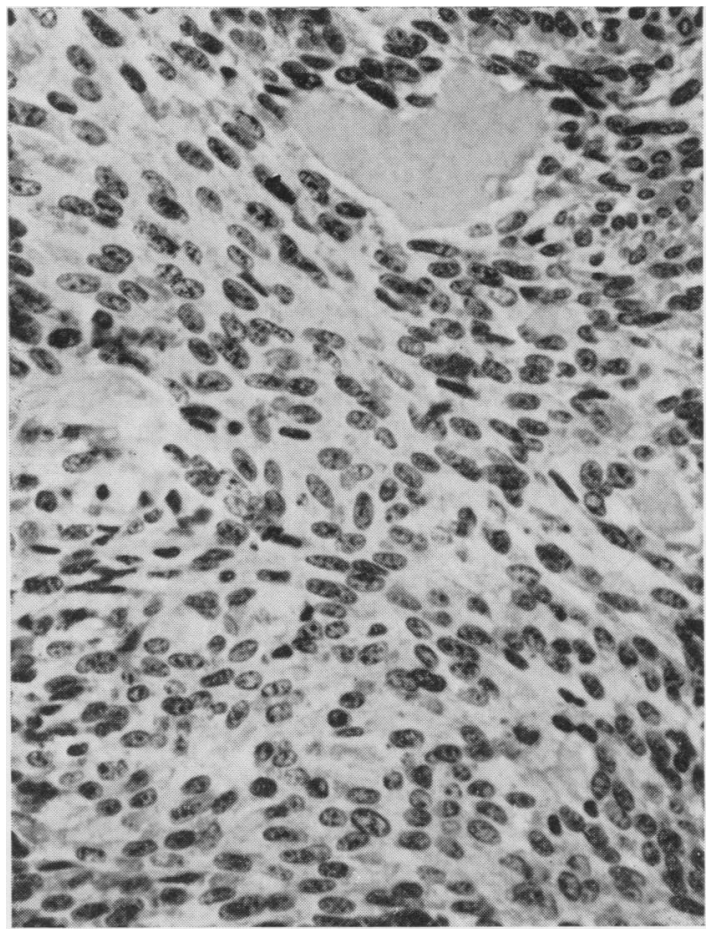

FIG. 5. H.E. $\times$ 400. Spindle cell pattern in medullary carcinoma.

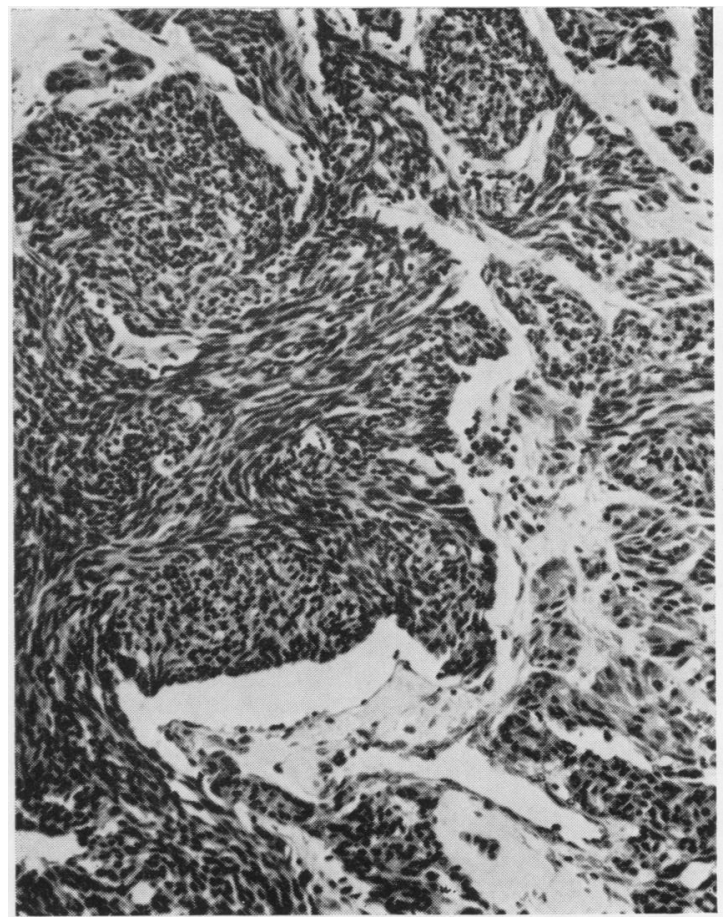

FIG. 6. H.E. $\times 160$. 'Oat cell' pattern in medullary carcinoma. 


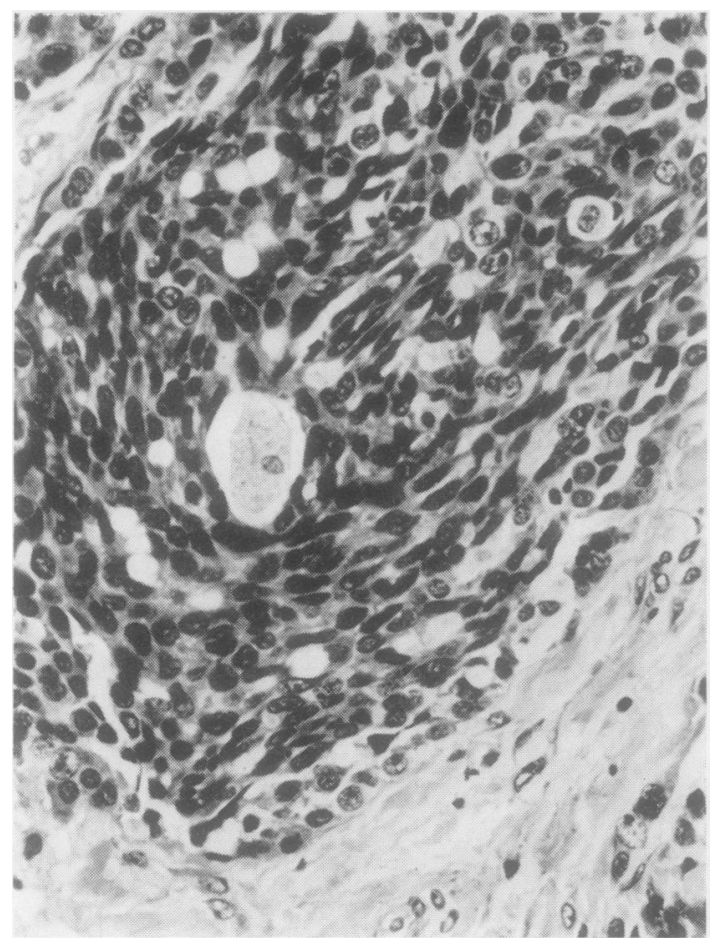

FIG. 7. H.E. $\times$ 400. Appearance of macrophage-like cells and vacuoles within spindle cell medullary carcinoma.

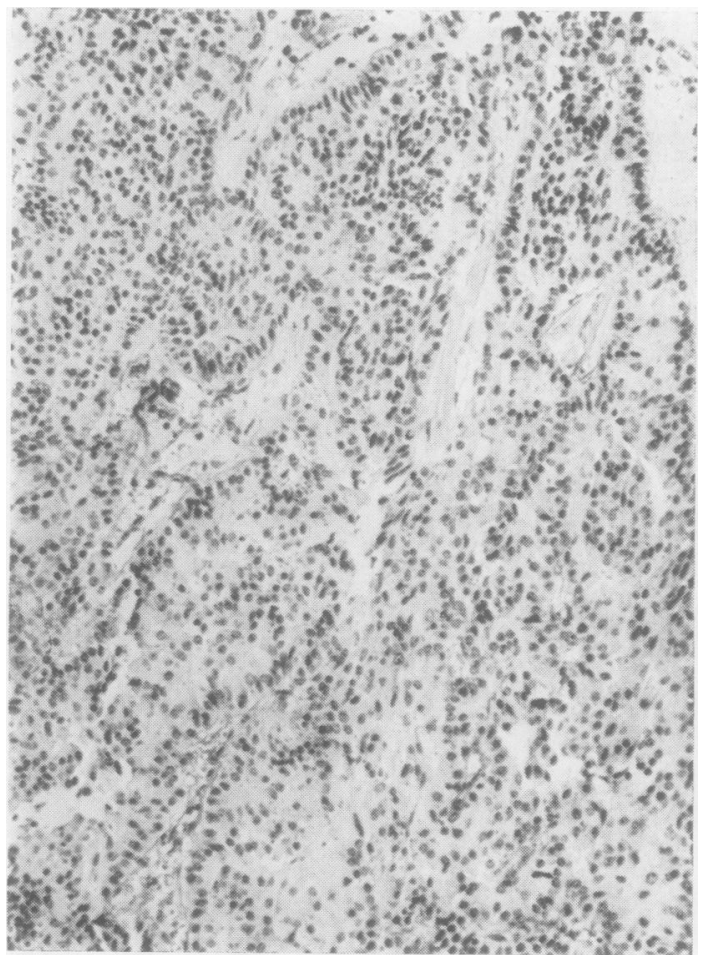

FIG. 8. H.E. $\times 160$. Palisading of peripheral cells in tumour clumps.

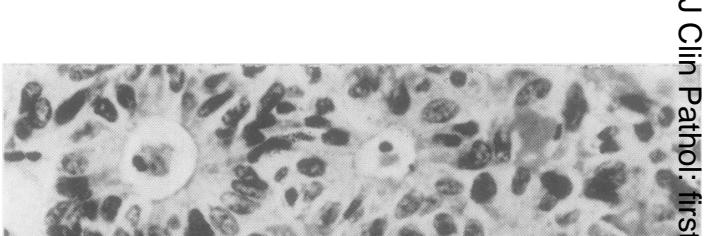

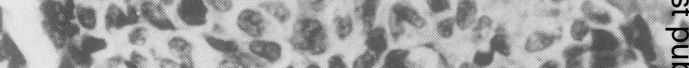

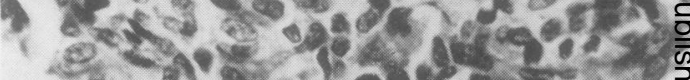

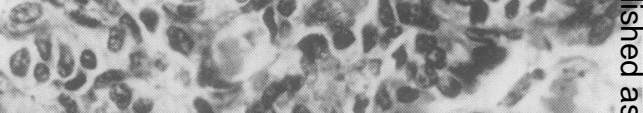

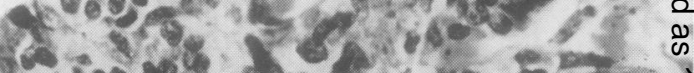

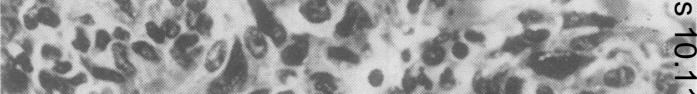
S.

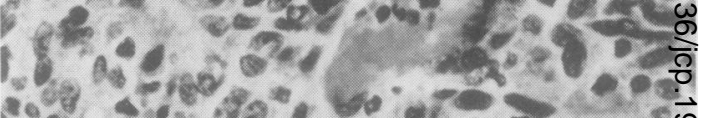

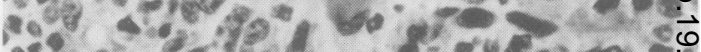

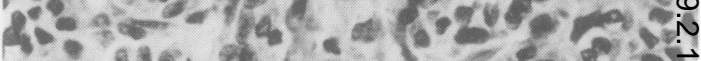

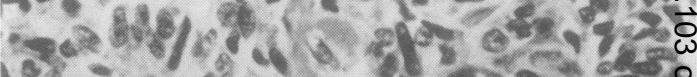

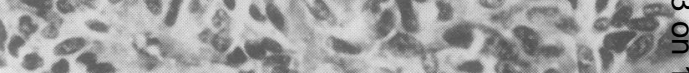

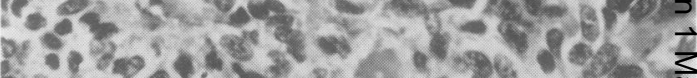

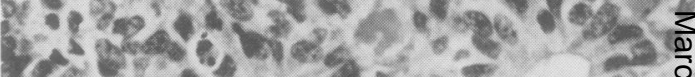

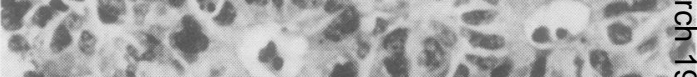

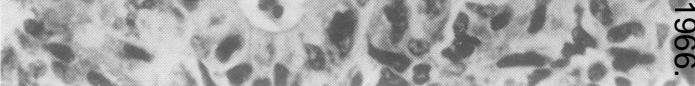

FIG. 9. H.E. $\times$ 400. Tubule formation in a medullao carcinoma.

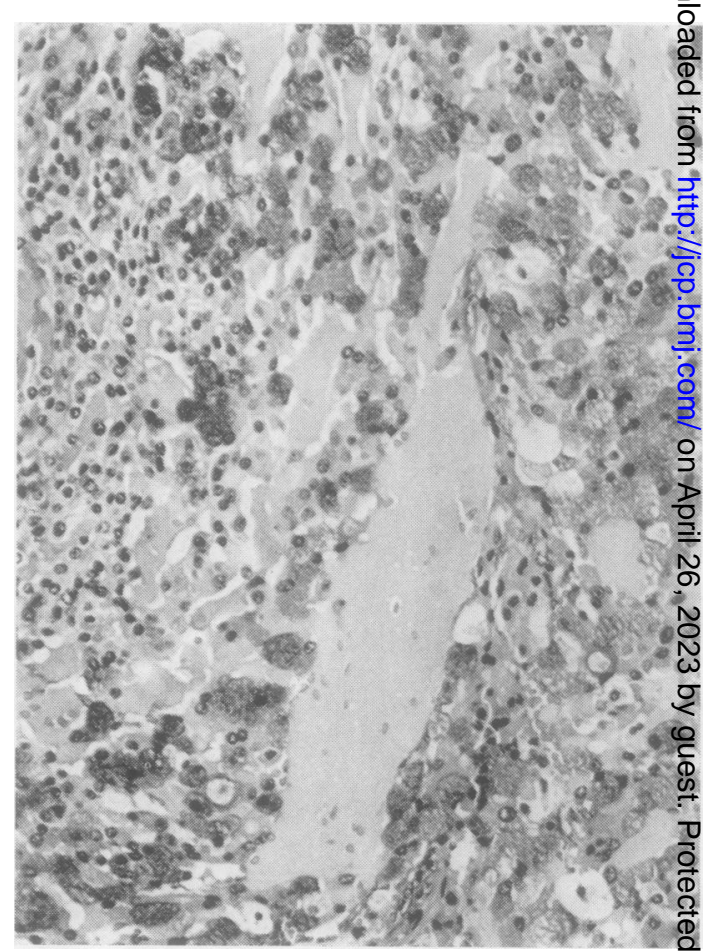

FIG. 10. H.E. $\times$ 200. Rare variant of tumour cetss containing intracytoplasmic basophilic mucin. 
or if rather more trabecular, of islet cell tumours. Tubule formation was present in small amounts in five cases (Fig. 9); these tubules occasionally contained a little basophilic mucin. In some of these cases a luminal brush border was seen. No colloid secretion was noted and no true papillary structures were present. In three cases tumour cells with intracytoplasmic basophilic mucin were seen, resembling goblet cells (Fig. 10). While true tubular structures were uncommon, structures resembling rosettes were occasionally seen; these consisted of elongated cells orientated around a small central area of amyloid. Areas of necrosis in the tumour were extremely unusual, extensive necrosis being found in only one case. Focal calcification, however, was quite common, being found in more than half the cases (Fig. 11); extensive calcification was present in seven tumours. Many of the calcified deposits were small and rounded and resembled psammoma bodies except that they did not show the same regularity of lamination. Occasionally calcification definitely within amyloid was observed, and the rounded bodies were thought to represent calcification in small deposits of amyloid. Cystic areas in the tumour were extremely uncommon, being seen only twice.

The stroma of the tumour was variable, in some cases forming thin connective tissue bands between tumour cell groups but in most cases consisting of dense relatively acellular collagen.

The properties of the tumour cells were investigated by a number of techniques other than haemalum and eosin. Periodic-acid-Schiff technique showed positive material in small amounts in tumour cytoplasm, and plentiful small granules in the clear macrophage-like cells. In part this was due to the presence of glycogen as shown by Best's carmine method. The tumour cells were weakly positive to Alcian blue. Well over half of the 34 cases tested contained a few cells positive with the Glees Marsland and Bodian argyrophil techniques; a few cases were strongly positive.

\section{AMYLOID}

In the majority of cases a considerable amount of amyloid was present in the primary tumour and in the metastases (Figs. 12 and 13), although sometimes unevenly distributed throughout the tumour. The smaller deposits of amyloid were present in between the tumour cells, sometimes closely apposed to the cell membrane or even within the cytoplasm. Larger amounts formed interlacing trabeculae between the cells, and massive deposition was present as irregular masses either within the sheets of tumour cells or in the stroma. Sometimes tumour cells were arranged around amyloid deposits in a pseudo-follicular

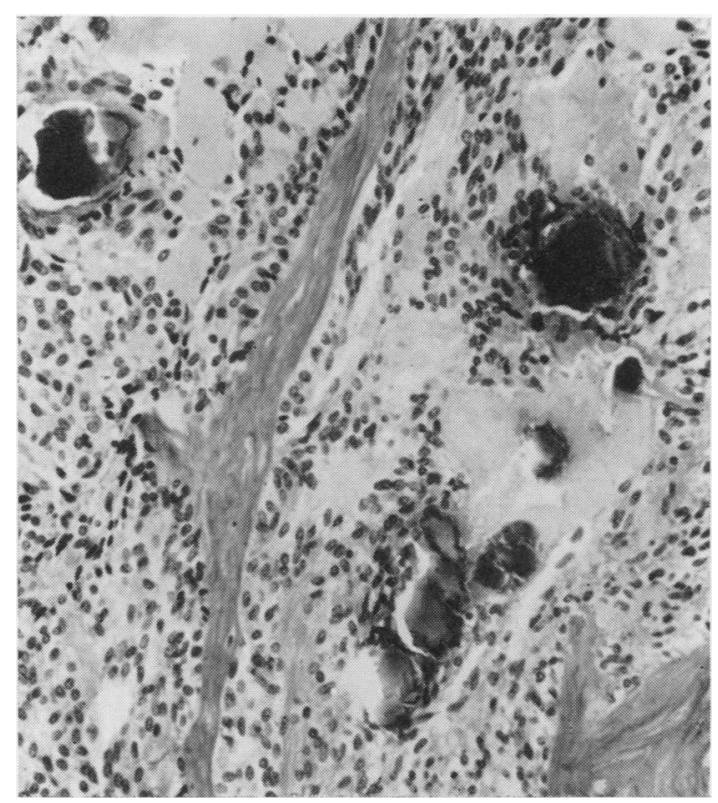

FIG. 11. H.V.G. $\times$ 200. Calcareous deposits in amyloid are shown as darkly staining irregular masses.
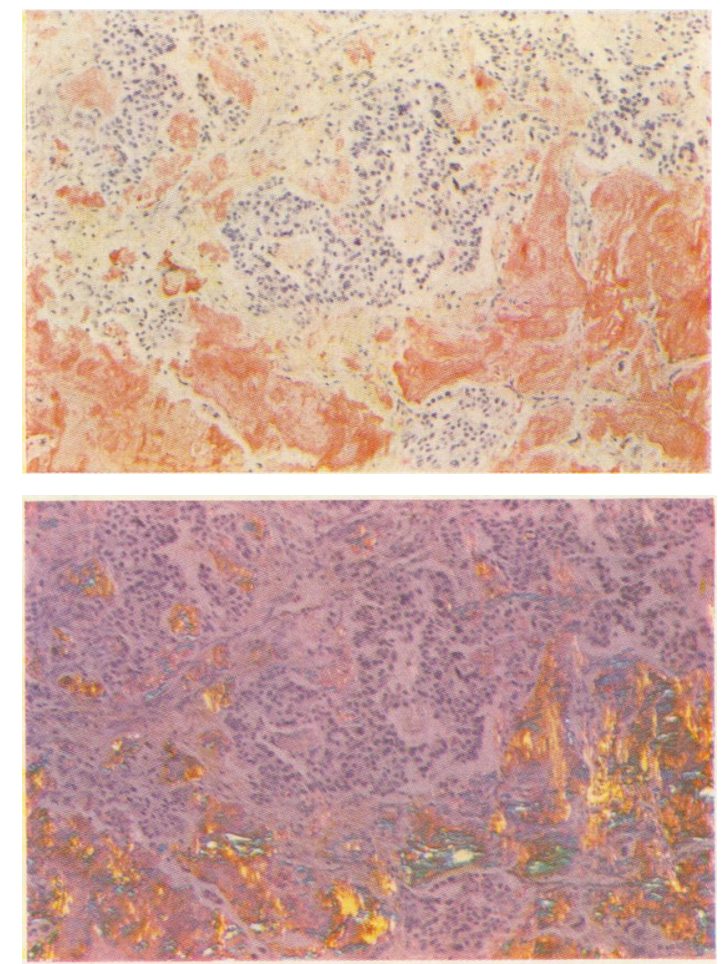

FIG. 12. and 13. Medullary carcinoma showing Congo red staining of amyloid, and same area (Fig. 13) viewed between crossed polaroids showing characteristic green colour of the stained amyloid. Congo red and haemalum. $\times 160$. 
pattern. Scattered small deposits were not uncommon in the stroma and were seen in the adventitia of small vessels within and immediately adjacent to areas of tumour. Amyloid in small amounts, remote from the tumour, was found in two cases with longstanding widespread secondary carcinoma. The major site of deposition was the renal glomeruli. This will be the subject of a further report.

A foreign body giant cell reaction to the amyloid deposits was noted in a few tumours (Fig. 14); in some instances it was difficult to be certain whether multinucleated giant cells associated with amyloid were of macrophage or tumour origin. In three cases round concentrically laminated masses of amyloid were present in the stroma. These showed a maltese cross pattern of birefringence when viewed between crossed polaroids.

\section{SPREAD OF THE TUMOUR}

In nine cases the tumour was sharply demarcated from the surrounding thyroid tissue by a complete or partial fibrous capsule (Fig. 15). In the majority of tumours the adjacent thyroid parenchyma was irregularly engulfed by advancing tumour, and scattered colloid containing non-neoplastic thyroid follicles was often seen completely surrounded by tumour cells in the outer third of the carcinoma (Fig. 16). Small interstitial groups of tumour cells separated from the main mass were uncommon; lymphatic permeation was seen in a few cases. The major early site of metastasis was undoubtedly the cervical lymph nodes. In many cases the initial complaint of a lump in the neck was due to lymph node enlargement; in several cases the thyroid tumour was not resected until several years after the removal of tumour-containing lymph nodes from the neck. Three at least of these tumours had originally been diagnosed as carotid body tumours on histological grounds. Cervical lymph node involvement was present at the time of diagnosis of thyroid

\section{TABLE I}

DISTRIBUTION OF METASTASES IN 20 POST-MORTEM CASES OF MEDULLARY CARCINOMA

Site of Tumour Deposit

Number of

Cases

1 Local lymph nodes

(including mediastinum)

2 Lungs

3 Liver

4 Adrenals

5 Bones

6 Pleura

7 Heart

8 Ovary

9 Pancreas

10 No disseminated tumour carcinoma in two-thirds of the cases. At necropsy the pattern of distant metastases is shown in Table I. At times the anterior mediastinal lymph nodes were matted together by tumour to form a large retro sternal mass; the hila of the lungs were also occasior ally involved. In one case there was direct bronchi invasion, and a bronchoscopic biopsy showe secondary medullary carcinoma. Apart from this local involvement of neck and mediastinum the commonest sites of distant spread were the lung? liver, adrenals, and bones.

\section{OTHER THYROID FINDINGS}

The carcinoma was present in the right lobe in $24 \overrightarrow{64}$ the 35 instances in which the side was recorded. The non-neoplastic thyroid parenchyma was in nearly adf cases normal. No case showed severe focal thyroiditis and evidence suggesting thyrotrophic stimulation was not seen. Uncommonly follicular adenomas separa from the primary medullary carcinoma were notec In three examples small areas resembling embryonat adenoma were found within the carcinoma. In one $\overrightarrow{0+}$ the 67 cases there was also a papillary carcinoma the thyroid. This patient had noted a goitre from the age of 8 ; subtotal thyroidectomy at the age of showed a gland almost entirely consisting of papillay carcinoma. She had repeated operations for recumrence of carcinoma, all showing only papillari carcinoma, until at the age of 28 the residual thyroid tissue from one lobe was resected an contained discrete nodules consisting entirely of typical medullary carcinoma, and quite distinct frog any papillary tumour.

\section{CLINICAL DETAILS}

The sex incidence, female to male, was $1 \cdot 3$ to $1 \cdot$. The age of the patients at presentation to hospital with a symptom, usually swelling of the neck, referable to the thyroid carcinoma varied widely. The youngest was 10 when he was first seen and the oldest 79 with a fairly uniform incidence over the adult decades (Fig. 17). In four patients the thyrod enlargement was first noted before the age of 20 , and six patients gave a history of five or more years of thyroid swelling before they attended hospital. The usual course of treatment adopted was subtot thyroidectomy with removal of affected nodes. some cases radiotherapy was used following operas tion and sometimes following the diagnosis of anaplastic carcinoma. It is difficult to assess te results of radiotherapy but no case of dramatic shrinkage was observed and we doubt if the natur? history of the disease is significantly altered. Wherfe 


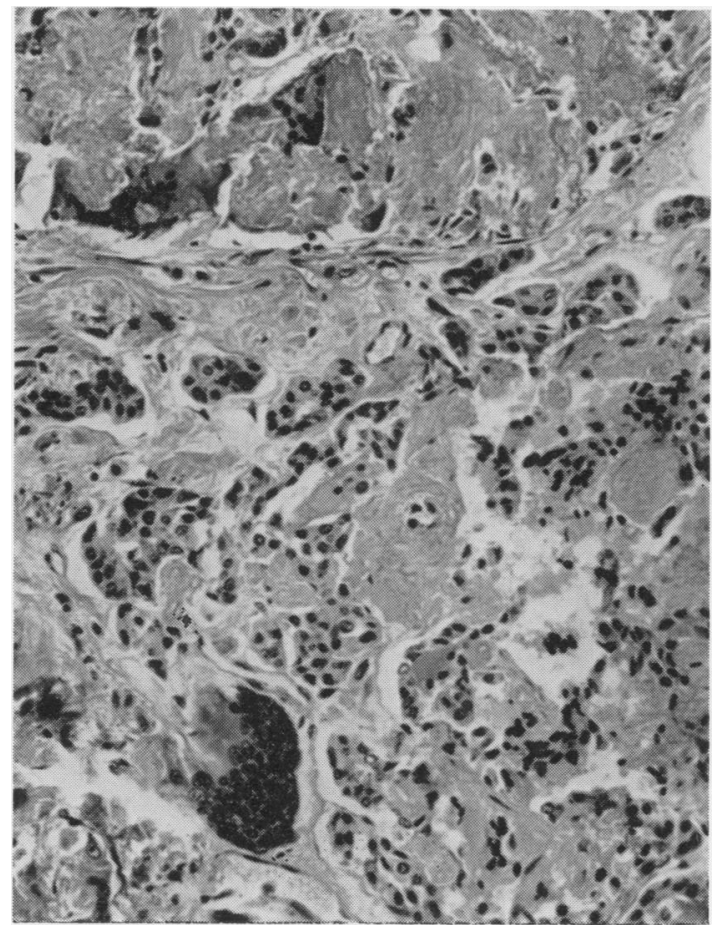

FIG. 14 .

FIG. 14. H.E. $\times$ 200. Multinucleate giant cells of foreign body type related to deposits of amyloid.

FIG. 15. H.E. $\times$ 50. Low-power view of the edge of an encapsulated medullary tumour.

FIG. 16. H.E. $\times$ 40. Low-power view of advancing edge of a medullary carcinoma showing engulfed non-neoplastic thyroid follicles.

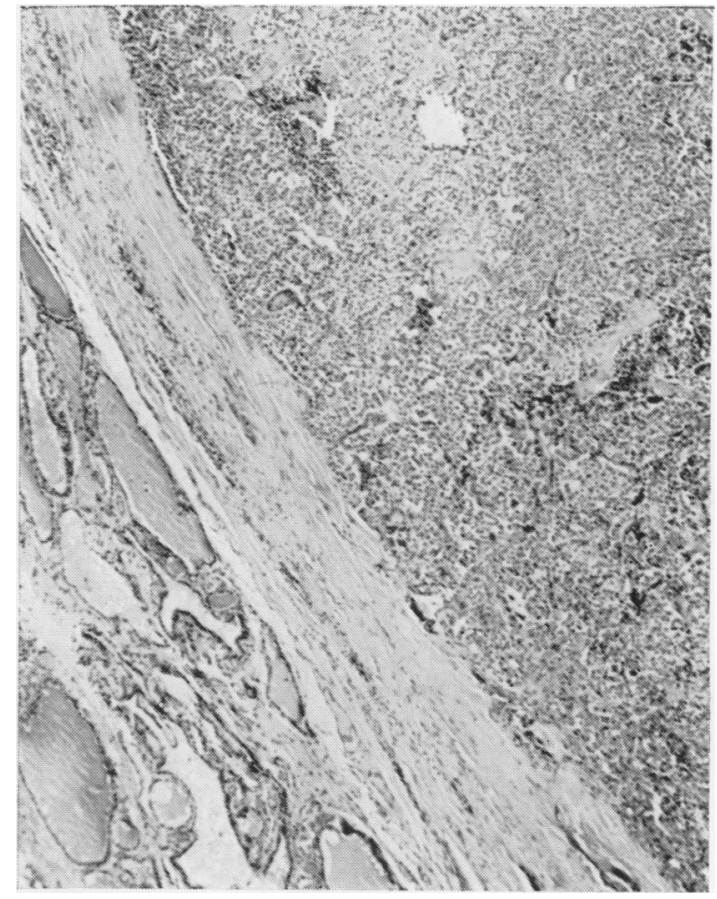

FIG. 15 .

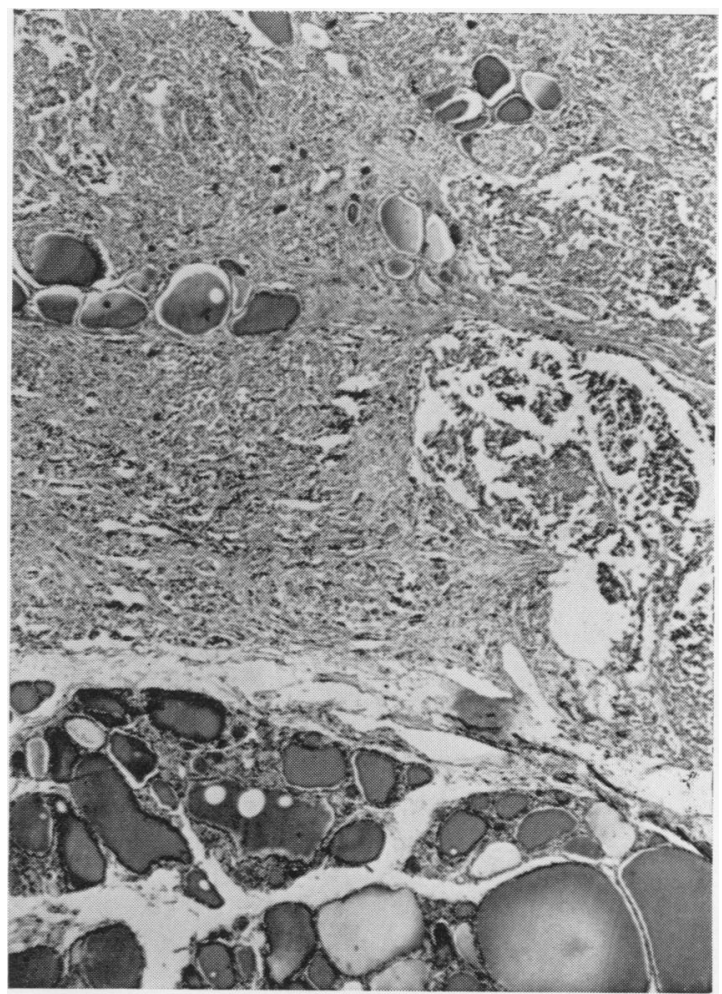

FIG. 16 . 


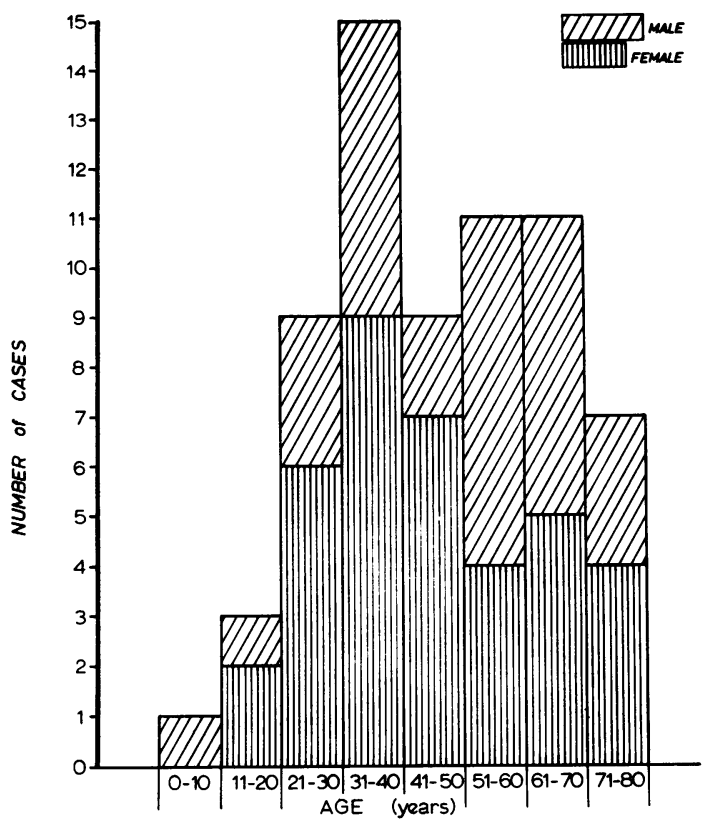

FIG. 17. Incidence of medullary carcinoma of thyroid by sex and age, in decades, at presentation. attempts were made to study the radio-iodine uptak of the tumour by external scanning or by aut $\theta_{-}$. radiography, to induce it to concentrate radio-iodirse by thyroid ablation, or to treat the tumour wi radio-iodine, the results were completely negative The only systemic symptom which occurred wif unexpected frequency was diarrhoea. Severe, pr\& longed, unexplained diarrhoea was found in 14 case In view of the lack of evidence of radio-iodine concentration by the tumour it may be due to the production of a humoral factor other than thyroxin and will be the subject of a separate report.

A variety of other diseases was found in this seris of thyroid carcinoma, but with two exceptions none of them was considered to be of any significance Two cases also had phaeochromocytomas, in one patient bilateral. Both these patients also had smal papillary tumours of the conjunctiva, lips and tongle which on histological study were shown to be neuromas. Full reports of these patients are to published (Williams and Pollock, 1966). Three othe्न cases were also described as having similar papillary tumours, in one case of the buccal mucosa only. man and his daughter were noted in our series both of whom had a medullary thyroid carcinoma. The daughter was the patient mentioned above, who,

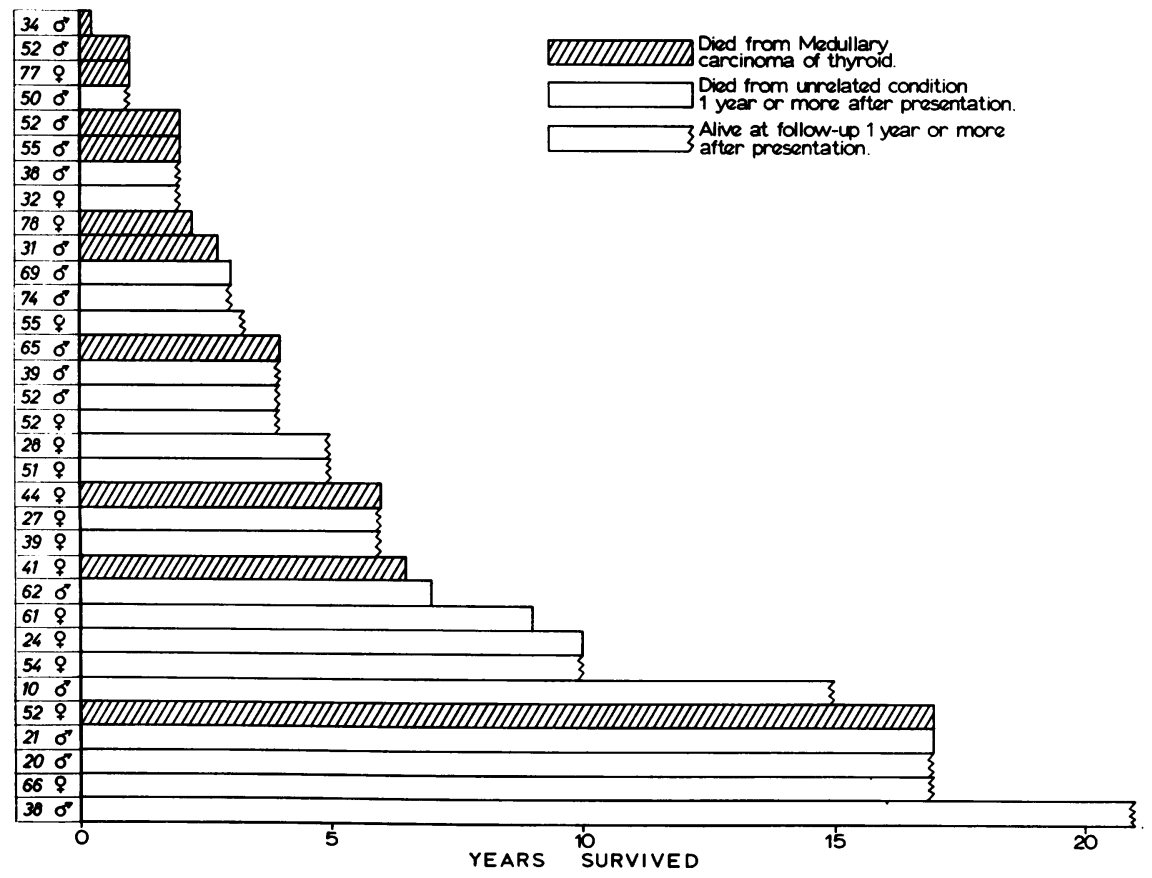

FIG. 18. Survival of patients from preserio tation with medullari carcinoma to death or latest follow up 윽 (including among the survivors only those cases traced for at $\mathrm{N}$ least one year). 
addition, had bilateral phaechromocytomas and facial neuromas.

The survival of these cases is often extremely long (Fig. 18). Eleven patients were known to have died of their disease, with a mean survival of 6.2 years from the first symptom (range nine months to 21 years) and a mean of $4 \cdot 1$ years from the time of presentation to hospital (range three months to 17 years). Twenty-two patients who died of unrelated causes or who were alive when last seen were followed up for periods of one year or more. This group showed a mean survival from onset of symptoms of $11 \cdot 2$ years (range one to 35 years) and a mean of 7.5 years from time of presentation to hospital (range 1 to 21 years). A total of 15 patients survived for five or more years from presentation while there were eight deaths in less than four years.

\section{DISCUSSION}

In this study we have confirmed and extended the pathological description of medullary carcinoma of the thyroid given by Hazard et al. (1959). These authors have stressed the major features of this tumour: the solid sheets and islands of cells with deposition of amyloid. In addition to these points we have laid emphasis on the cytological details, the frequent occurrence of binucleate cells and the frequent finding of focal calcification, which in most instances was probably calcification within amyloid. A comparison of our findings with those of the major American series is given in Table II.

Both Hazard et al. (1959) and Woolner et al. (1961) consider the presence of amyloid an essential diagnostic feature of this tumour. We used this criterion for the selection of our cases, and we would agree with Hazard et al. that the amount of amyloid present varied widely. In eight cases amyloid dominated the histological picture, with large areas of the section containing more amyloid than tumour. In almost half the cases amyloid was a conspicuous but not dominant feature. In 27 cases amyloid was found easily on searching after the cytological features of the tumour suggested the diagnosis, while in three cases only a small amount of amyloid was found after prolonged search. Three cases were excluded because no amyloid was found, although in other respects the diagnosis of medullary carcinoma seemed suitable. In common with other workers (Hazard et al., 1959; Vassar and Culling, 1961) we have not found amyloid in other thyroid tumours, although we have examined only a small series with special stains for amyloid. The presence of amyloid in a thyroid carcinoma is therefore of great value in establishing a diagnosis; its absence, particularly if only small amounts of tissue are available, should not exclude the diagnosis of medullary carcinoma.

Albores-Saavedra, Rose, Ibanez, Russell, Grey, and Dmochowski (1964) have investigated the amyloid in this type of tumour, and conclude that it is formed by the tumour cells themselves. We agree with their observations that amyloid may occasionally be seen within tumour cell cytoplasm, but we were unable to find the myeloma-like renal tubular casts they described in any of our necropsied cases. It has been suggested by Vassar and Culling (1961) that the amyloid in these tumours is an altered thyroglobulin secreted into the stroma. It is difficult to understand, if this were true, why amyloid is not seen commonly in association with colloid forming follicular and papillary carcinomas. We do not believe that there is any convincing evidence that the amyloid is related to thyroglobulin; these tumours in our experience do not make thyroglobulin and show no evidence of the ability to bind radio-iodine. Other tumours are known on occasion to show amyloid deposition in their stroma, and there seems no need to invoke an explanation involving thyroglobulin. It does seem, however, that the amyloid is in all probability manufactured by the tumour cells, or alternatively that the cells may secrete a factor leading to the formation of amyloid from a circulating glyco-protein. It is likely that the amyloid or amyloid-precipitating factor diffuses outwards locally; certainly vessels within and immediately adjacent to tumour deposits commonly show amyloid in their adventitia.

While the basic pattern of a solid cellular tumour, with the cells arranged in sheets or packets, and with

T ABLE II

COMPARISON OF FINDINGS IN THIS SERIES WITH THE TWO MAJOR AMERICAN SERIES OF CASES OF MEDULLARY CARCINOMA

\begin{tabular}{|c|c|c|c|c|c|c|}
\hline Series & No. of Cases & $\begin{array}{l}\text { Age Range at } \\
\text { Diagnosis }\end{array}$ & Sex Ratio $F$ to $M$ & $\begin{array}{l}\text { Range of Survival } \\
\text { in Years from } \\
\text { Diagnosis to Death } \\
\text { from Thyroid } \\
\text { Carcinoma }\end{array}$ & $\begin{array}{l}\text { No. of Patients } \\
\text { Available for } \\
\text { Follow-up } \\
\text { Surviving }>\text { Five } \\
\text { Years }\end{array}$ & $\begin{array}{l}\% \text { Patients with } \\
\text { Lymph-node Involve } \\
\text { ment at Operation }\end{array}$ \\
\hline $\begin{array}{l}\text { Hazard et al. } \\
\text { Woolner et al. } \\
\text { Present }\end{array}$ & $\begin{array}{l}21 \\
57 \\
67\end{array}$ & $\begin{array}{l}33 \text { to } 66 \\
14 \text { to } 74 \\
10 \text { to } 79\end{array}$ & $\begin{array}{r}2: 1 \\
1 \cdot 3: 1 \\
1 \cdot 3: 1\end{array}$ & $\begin{array}{l}0.3 \text { to } 27 \\
0.5 \text { to } 20 \\
0.3 \text { to } 17\end{array}$ & $\begin{array}{l}10 \text { out of } 21 \\
20 \text { out of } 37 \\
16 \text { out of } 33\end{array}$ & $\begin{array}{l}58 \\
59 \cdot 6 \\
66 \cdot 7\end{array}$ \\
\hline
\end{tabular}


amyloid in the stroma, was common to all the tumours we studied, a number of histological features, beside the amyloid content, showed considerable variation. It is of practical importance to determine whether any of the variables correlate with the great variation in prognosis shown by this tumour. Unfortunately the follow up of many of the earlier cases was very poor, but it was possible to make a comparison between seven patients who died from carcinomatosis within four years of diagnosis, and eight patients who were known to have survived at least 10 years from diagnosis. The conclusions from this remain tentative until we can obtain follow-up data on a considerably larger series. The various histological patterns of these tumours were scored on a four-point scale without knowledge of the survival of the case. No good correlation was found between the amount of amyloid and survival, or between either the frequency of binucleate cells or the degree of nuclear variation and survival. The amount of collagenous stroma was also without significance. Mitotic activity was noted in six of seven short-lived patients, and was absent in all but one of the long-survival patients. Calcification was present in only two of the seven short-term group but was found in all but one of the long-term group. Necrosis was noted in four of the seven short-term survivors, but was not found in any of the long-term survivors. Finally the spindle cell pattern was associated with a relatively poor prognosis, forming the major component in four of the seven patients who died in less than four years, while being found in only one of the patients who lived for more than 10 years and then as the less common cell type. These findings are not surprising; multinucleate cells and nuclear variation seem to be of less prognostic significance in endocrine tumours as a group than in other types, while the presence or absence of mitoses would be expected to be of importance in any tumour. The calcification in these tumours mostly occurred in amyloid; its presence or absence is probably related to the age of the amyloid and thus to the general growth rate of the tumour, as is the presence of necrosis. The composite picture we would draw of one of these tumours with a poor prognosis is a tumour with a predominant spindle cell pattern, fairly frequent mitoses, small areas of necrosis, variable amounts of amyloid but no calcification. In contrast the medullary carcinoma with a good prognosis is composed of polygonal cells with abundant granular cytoplasm, possibly showing moderate nuclear pleomorphism and fairly frequent binucleate cells but without mitoses, with variable amounts of amyloid and focal calcification.

One feature that we have not discussed in relation to prognosis is the absence or presence of a capsule.
An intact capsule was seen in two cases, while i蒙 seven a fibrous capsule was present but was breached by tumour trabeculae. One of the tumours with aq intact capsule was an incidental finding at necropsyg no secondary deposits were found; the other was removed from a patient of 25 ; our efforts to obtaiff a follow-up of more than one year have been withoug success.

We have not given any figure for the incidence of these tumours partly because a considerable propof tion of our cases has been contributed from other hospitals, and partly because a number of our ow cases had been mis-diagnosed in the past. Three of our cases were originally indexed as secondary carcinoma of the thyroid, and three as solid benigh adenomas of the thyroid. Before we are able to give an accurate figure for the incidence of this tumour we feel we should review every example of tumoug involvement of the thyroid in our files, whethen indexed as benign or malignant, primary or secon dary, and probably every cervical tumour maş reported as being a metastatic tumour from añ unknown site, or as a carotid body tumour. If $\vec{D}$ cervical lymph node contained follicular or papillarg carcinoma of the thyroid, then we feel confident that the great majority would be recognized, furthe surgery on the thyroid would follow, and the case would be included in our statistics as one of thyroia carcinoma. We know, however, that in a number of instances a mass of medullary carcinoma in the neck has been diagnosed as a carotid body tumour, whiR other examples have been called secondary car cinoma, primary unknown. One poorly fixeg example in this series was originally diagnosed dis plasmacytoma with massive amyloid deposition These past difficulties underline the importance of being aware of this type of thyroid tumour, but the make it impossible for us to give an exact figure foo the incidence of medullary carcinoma of the thyroid. However, our initial figures, taken only from those cases included in The London Hospital index as carcinoma of the thyroid, include 15 examples of medullary carcinoma out of a total of 135 thyroid carcinomas. Further study has revealed seven more examples of medullary carcinoma, but has als shown that a number of tumours we would now undoubtedly call carcinomas were termed papillate adenomas up to about 25 years ago. We think that medullary carcinoma may well form more than the $3.5 \%$ (Hazard et al., 1959) or $6.5 \%$ (Woolner et als, 1961) of all thyroid carcinomas, and its incidence is probably in the region of $10 \%$ or more.

With regard to some of its features, medullar carcinoma is a very variable tumour. The ages presentation of our cases were widely scattered, and the survival rate following diagnosis varied between 
three months and 21 years. Some of the histological features were also very variable. The broad spectrum, however, does not imply that medullary carcinoma is merely a histological variant of other types of thyroid carcinoma, in the sense that both papillary and follicular carcinoma may have Hürthle cell variants. In support of the distinctive nature of medullary carcinoma of the thyroid is the part it plays in various tumour syndromes. The reasons for its association with phaeochromocytoma, and for its association with multiple mucosal neuromas, are probably genetic. Only one of the cases of phaechromocytoma and thyroid carcinoma reviewed by Williams (1965) was unequivocally diagnosed as papillary carcinoma of the thyroid, while after review of the histological findings in five examples, 13 of the 21 cases were described as medullary carcinomas. It seems that the association of thyroid carcinoma and phaochromocytoma is specifically with medullary carcinoma. It is also likely that the association of thyroid carcinoma with multiple mucosal neuromas is again specifically with medullary carcinoma, as we have found evidence for this association in five of our 67 cases, while we have not found it with any other type of thyroid tumour.

Both these associations may be familial; a father and daughter with medullary carcinoma and mucosal neuromas are included in our series. The daughter also had bilateral phaeochromocytomas. We have traced four other families in the literature (Williams, 1965 ) with more than one member proven to have thyroid carcinoma; in three of these multiple examples of phaeochromocytoma were also found Eleven members of these five families have had thyroid carcinoma which in eight was considered to be medullary in type. We know of no evidence that other types of thyroid carcinoma can be familial.

These clinical findings support our contention that medullary carcinoma of the thyroid is an important and distinct entity, clearly separable from other types of thyroid carcinoma.

We are particularly grateful to Drs. Sybil Robinson and A. G. Stansfield, Professors C. V. Harrison and M. Price for allowing us access to their files, and to Drs. Raymond Greene and A. Stuart Mason, and Messrs. J. E. Piercy, J. E. Richardson and Selwyn Taylor for permitting us to study the clinical records of their cases. We would also like to thank the numerous pathologists and clinicians who helped in the study of individual cases. We are grateful to Miss R. Cresswell for secretarial help.

\section{REFERENCES}

Albores-Saavedra, J., Rose, G. G., Ibanez, M. L., Russell, W. O., Grey, C. E., and Dmochowski, L. (1964). Lab. Invest., 13, 77. Brewer, D. B. (1964). Renal Biopsy, p. 20. Arnold, London.

Hazard, J. B., Hawk, W. A., and Crile, G. Jr. (1959). J. clin. Endocr., $19,152$.

Horn, R. C., Jr. (1951). Cancer (Philad.), 4, 697.

Ladewig, P. (1945). Nature (Lond.), 156, 81.

Laskowski, J. (1958). Nowotwory, 7, 23.

Russell, W. O., Ibanez, M. L., Clark, R. L., and White, E. C. (1963). Cancer (Philad.), 16, 1425.

Vassar, P. S., and Culling, C. F. (1961). Amer. J. clin. Path., 36, 244 Williams, E. D. (1965). J. clin. Path., 18, 288.

- , and Pollock, D. J. (1966). J. Path. Bact., in the press.

Woolner, L. B., Beahrs, O. H., Black, B. M., McConahey, W. M., and Keating, F. R. Jr. (1961). Amer. J. Surg., 102, 354. 